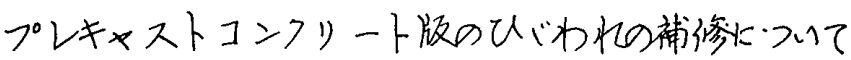

会員O请水吉盛 山口哲生

\section{§.1 目的}

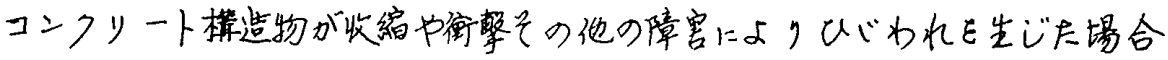

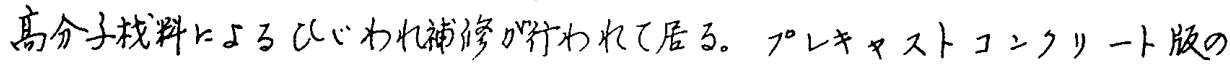

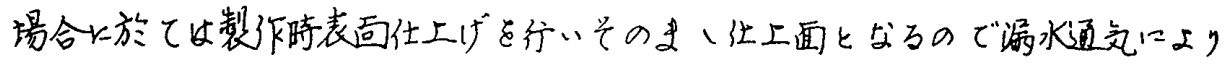

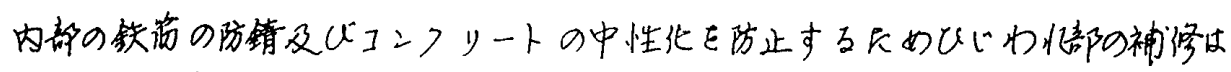

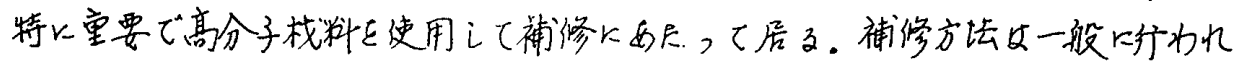

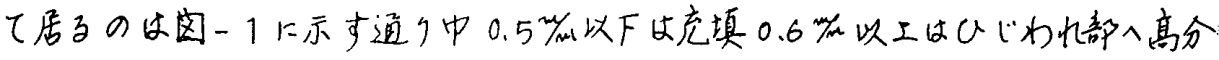

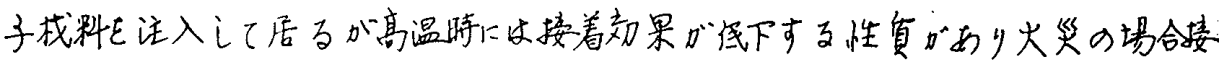

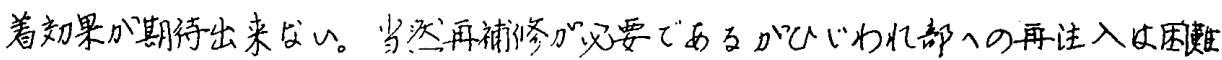

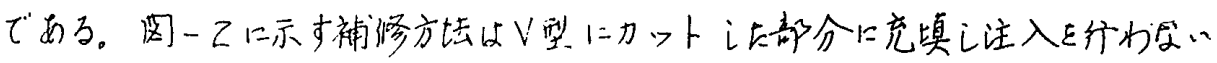

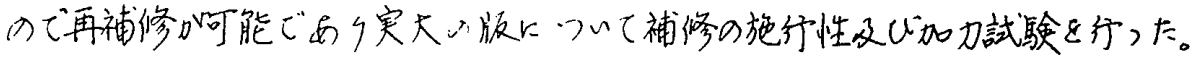

$\xi .2$ 試験

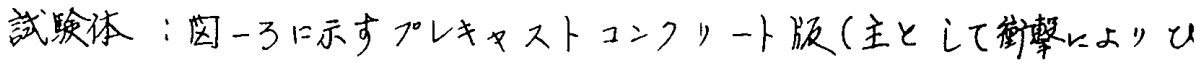

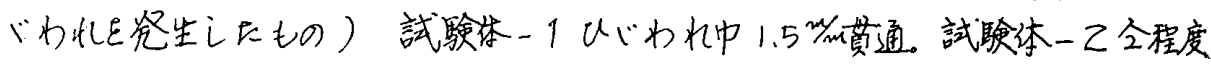

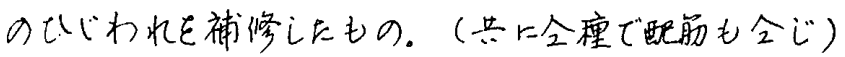

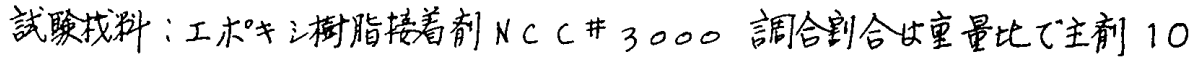

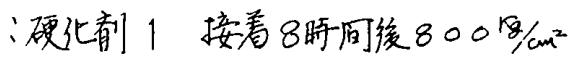

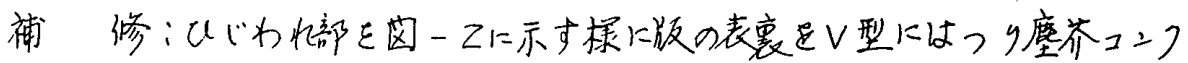

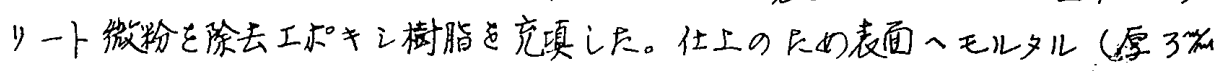
)を理布亡た。

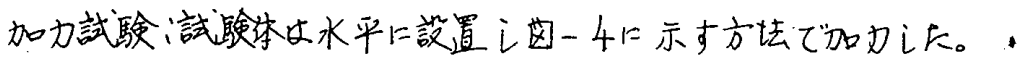

$\xi .3$ 試験結果

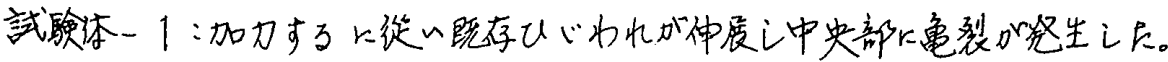

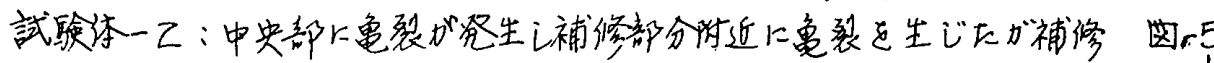

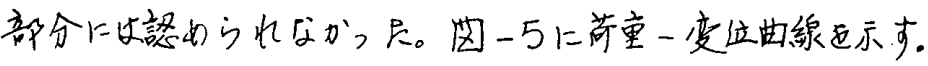

\section{.5.4 考察}

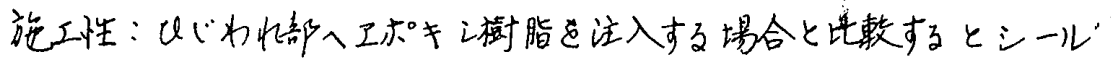

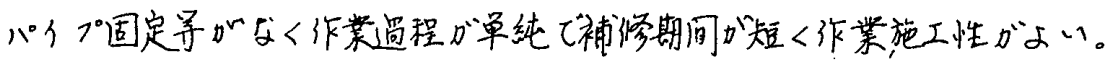

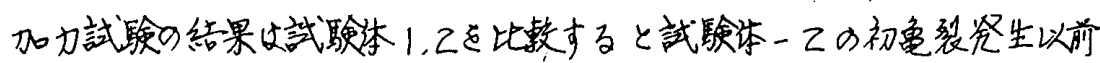

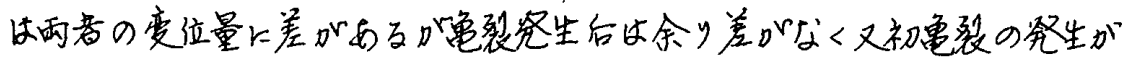

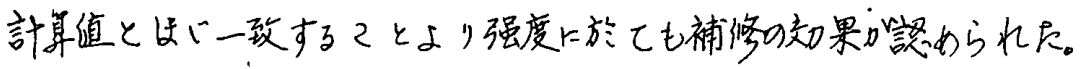

プレキャストュンクリーート版の補修の绦には

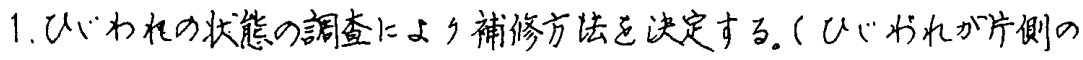

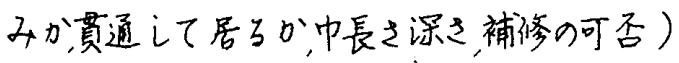

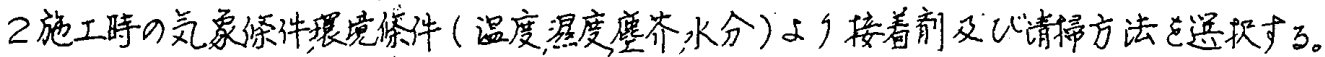

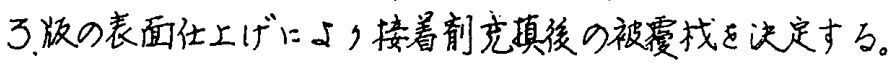
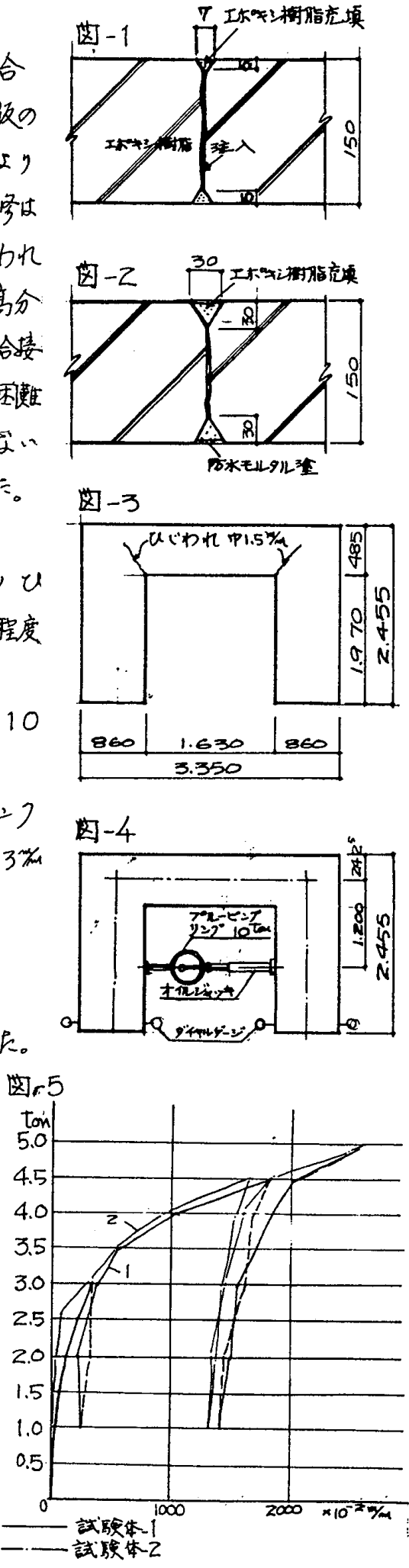